\title{
EVALUATION OF COLLAPSE MECHANISM OF TELECOMMUNICATION TOWER
}

\author{
M. Yanda ${ }^{1, *}$, O. S. Abejide ${ }^{2}$ and A. Ocholi ${ }^{3}$ \\ 1, Dept of Civil Engineering, Umaru Ali Shinkafi PolyteChnic Sokoto, Sokoto State, NIGERIA \\ 2, 3, Department of Civil Engineering, AhMAdu Bello UniverSity, ZARIA, KADUNA StATE, NIGERIA \\ Email addresses: 1 mymyanda7@gmail.com, 2 abejideos@yahoo.com, 3 amanaocholi@gmail.com
}

\begin{abstract}
This paper presents evaluation of a $67.12 \mathrm{~m}$ high telecommunication tower with the objectives of applying the Finite Element Method (FEM) in modelling it, analysing it under Nigerian wind loads from five different wind zones (Zone 1, Zone 2, Zone 3 Zone 4 and Zone 5 with basic wind speeds as $42 \mathrm{~m} / \mathrm{s}, 45.8 \mathrm{~m} / \mathrm{s}, 50 \mathrm{~m} / \mathrm{s}, 55 \mathrm{~m} / \mathrm{s}$ and $56 \mathrm{~m} / \mathrm{s}$ respectively). The collapse mechanism of the tower was predicted using the Mechanism Method. The tower was modelled and wind load was calculated on it and analysis shows that there is mechanism for the tower to collapse under dynamic wind loads as plastic hinges are developed at the joints and along bracing members. The most severe wind load was used in the plastic analysis conducted and it shows that when the plastic hinges developed at the lower section of the tower, the three mechanisms are more critical compared to when it develops at other sections of the tower. Also, using such load as the collapse load, when the plastic hinges developed at any section of the tower, combine mechanism is more critical and hence the tower is likely to collapse due to failure of both leg members and bracing members.
\end{abstract}

Key words: Collapse, Mast, Steel Structure, Analysis

\section{INTRODUCTION}

Communication plays a great role in our societal development and the demand for reliable communications is on the increase. Due to on-going expansion in the information, communication and technology sectors, such as digital television, and mobile telecommunications, there is an increasing need to better utilize the capacity of the existing towers and optimize the capacity of new structures. Also, the demand for more towers to be erected in urbanized areas has created the need for far more reliable structures [1]. Masts and towers are in three forms, based on their height, the monopoles which rises to about $70 \mathrm{~m}$, the self-supporting lattice towers, which is between $120 \mathrm{~m}$ and $300 \mathrm{~m}$ in height, and the guyed masts, which rises up to a height of $620 \mathrm{~m}$ [2].

A self-supporting tower (free-standing tower) is constructed without guy wires. Self-supporting towers have a larger footprint than monopoles, but still require a much smaller area than guyed masts. Self-supporting towers can be built with three or four sided structures. They are assembled in sections with a lattice work of cross braces bolted to three to four sloping vertical tower legs [3].

There are a variety of reasons for steel masts and towers collapse. Some collapses can be due to human error, such as faulty design or poor construction, lack of regular maintenance, accidental damage, and so forth. Other causes include malicious mischief, metal fatigue, and the use of substandard material. However, most failures are caused by rare natural events such as; blizzard, hurricane, tornado, and earthquake, which vary in intensity and also time dependent [4]. Thus, there is need to evaluate the collapse mechanism of these steel masts and towers in a probabilistic way,

\footnotetext{
* Corresponding author, tel: +234-803-656-5172
} 
while considering all the associated parameters inducing failure of the structure system or member.

\section{LITERATURE REVIEW}

\subsection{Loadings on Masts and Towers}

Masts and Towers are subjected to different types of loads. The loadings depend on locations the structures and climatic conditions of these locations. These includes dead load from the tower structure, ice load on the tower structure, erection and maintenances load, wind load, earthquake load. There are also additional loads peculiar to electrical transmission masts and towers, which includes ice load or wet load on conductors and equipment, loads from conductor tensile forces etc [5].

Wind load is the predominant load on masts and towers, but in some areas also the atmospheric icing of the structure may have a great effect on the design of masts and towers due to its influence on the loading of these structures. Especially when icing is combined with wind, this may be decisive for the design in some countries. The wind load acting on the structure is in form of horizontal load where the structure is considered as a cantilever beam with one end fixed at the bottom (butt end) and the load applied at the top end [6].

Earthquake forces act on masts and towers, most especially tall masts in a way that the differential vertical movements between mast base and guy anchorage points may lead to drastic force redistribution and the possibility of buckling of the mast [7].

Wind is a dynamic load and slender structures like towers and masts are sensitive to dynamic load because they are flexible and have very low structural damping characteristics. It is therefore essential that towers and masts are analysed in order to reveal their response to such dynamic load. In the case of free standing towers, since their natural frequencies usually are well separated, the response of the structure to wind gusts is always determined considering their fundamental mode of vibration. This enables simplified analysis procedures to be adopted using appropriate gust response factors. Nevertheless, care needs always to be exercised in the design, especially for heavily affected tower configurations. When it comes to guyed masts the analyses are not simple, rather complex. This is owing to the need for analysis of both masts and the guys thereby determining their response to the wind load [8].

The capability of a tower to carry the wind and imposed loads on it largely depends on the structural composition of that tower. Also, the robustness of a tower depends on the surface area of equipment (for example, antennas), coaxial cables, brackets and other equipment mounted on the tower and exposed to the wind. The wind load is proportional to the area of the exposed structure and distance from the attachment to the ground. Curved and perforated shapes (grids and trusses) offer less wind resistance and are therefore preferred to achieve a low wind load. Solid dishes are quite vulnerable to wind load and should be avoided in windy environments. When it is considered necessary, wind tunnel tests may be performed to evaluate the wind action [3].

\subsection{Historic Record of Some Masts that Failed due to Dynamic Effect}

Over the years several cases of masts and towers failure has been recorded by some authors and researchers. According to [7] the tallest mast in the world, the $648 \mathrm{~m}$ high long wave mast in Konstantynow, Poland collapsed in 1991. A number of incidences of mast failure and collapse across the globe due to some natural influences was also recorded [4]. These include large storms in 1973, 1975, 1983, and 1994 that caused 48 of the 65 failures that occurred during those years. The worst single year was 1983, in which 26 failures occurred. The most storms that caused failures in any one year were four, in 1989. Also between December 1 and March 31 of the same year in which more than $90 \%$ of the failures occurred.

In Nigeria, Thunderstorms and strong wind had led to collapse of several masts and towers in the past and present. In 2012, two masts erected within the precinct premises of H.F.P shopping Centre, Dolphin Estate, Lagos Island, close to a church collapsed while worshipers were observing "Night Vigil". Properties worth millions of Naira were destroyed. In May, 2013, a faulty hollow mast had caved in and in the process collapsed on a 52-year old man. The mast was said to have fallen from a 2-storey building and crushed him to death [8]. Similarly, in 2014, a Globacom mast collapsed at Odukpani Local Government Area of Cross River State killing three people. This happened following a rainstorm that came with severe wind. 


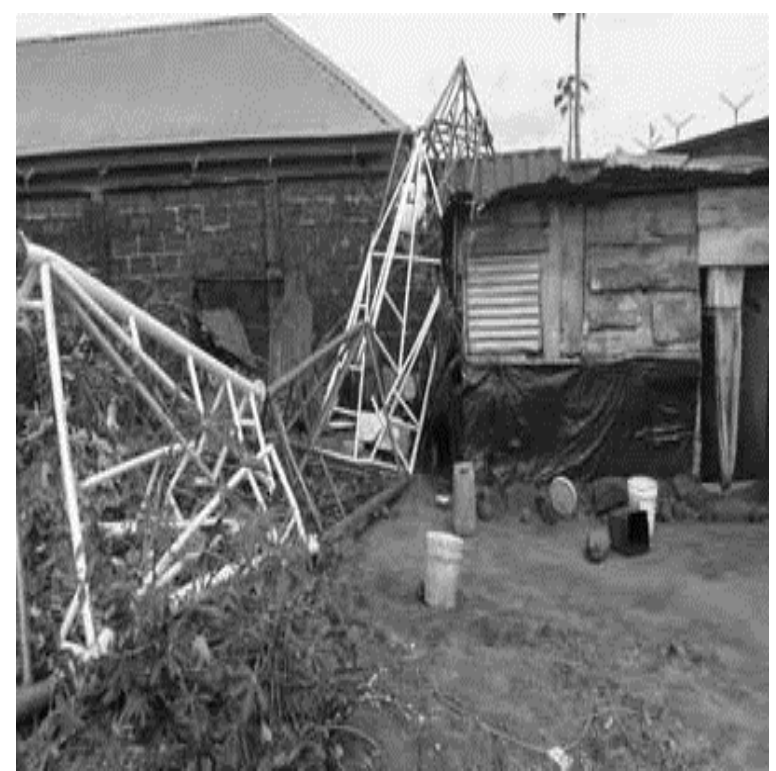

Figure 1: Citi Bank Mast Collapse in Lagos

The Lagos State Urban Furniture and Regulatory Unit, UFRU, however, has been battling with users of substandard masts who have refused to heed to directive to replace hollow pipes with the global standard of galvanized steel masts which are not susceptible to collapse [8]. Figures 1 and 2 shows some collapsed masts in Lagos and Port Harcourt metropolis respectively.

\section{MATERIALS AND METHODS}

The steel lattice towers under study covers a big part of the steel telecommunication towers used in Nigeria, where large number of these towers were built in the recent decades (1990s to 2000s) and are characterized by a number of construction arrangement. The present work deals with the study of the most commonly used 4-leged self-supporting steel lattice towers. In this work analysis was conducted on the towers. The analysis focused on their behaviour especially regarding the influence of environmental action, such as wind action which is the only environmental influence, with respect to loading, that is peculiar to Nigeria, and as well the combined effect of the structural capacity. The wind zones in Nigeria, as classified by [9], (zone 1, zone 2 , zone 3 , zone 4 and zone 5) were considered in this work. All the zones were considered with their maximum basic wind speeds as $42 \mathrm{~m} / \mathrm{s}, 45.8 \mathrm{~m} / \mathrm{s}$, $50 \mathrm{~m} / \mathrm{s}, 55 \mathrm{~m} / \mathrm{s}$ and $56 \mathrm{~m} / \mathrm{s}$ respectively.

Information obtained from the [10] and [11] were used as the basic data for the investigation. Below is

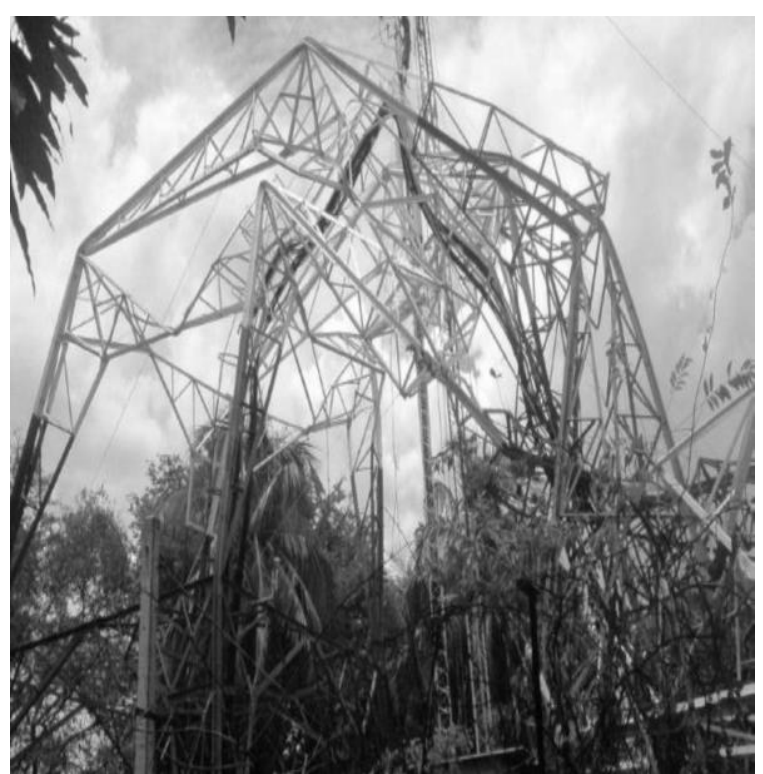

Figure 2: Collapsed Telecom Mast in Port Harcourt

the Nigerian map showing the locations of the wind zones as captured in their work.

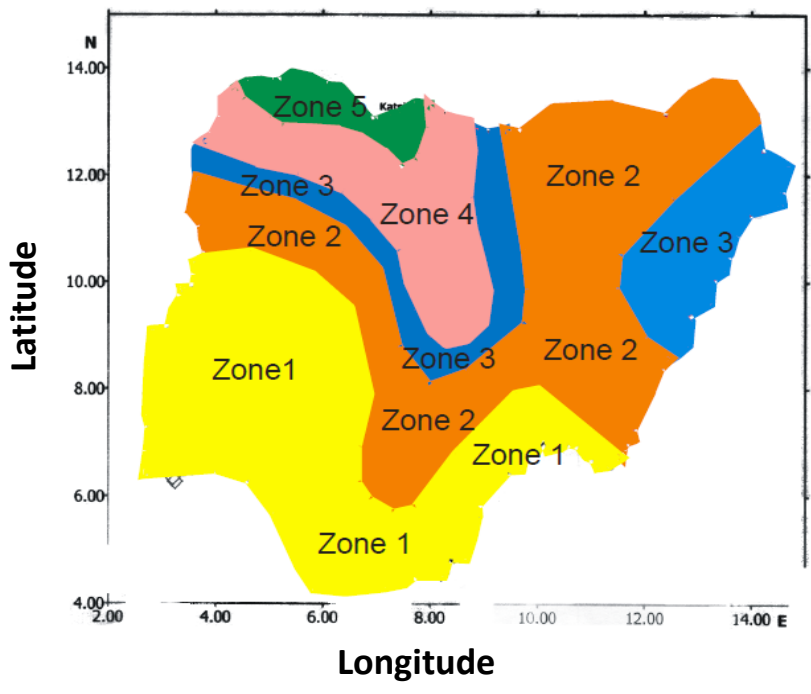

Figure 3: Nigerian Wind Zones [9]

The most severe wind load produced by these wind speeds was also applied on the tower for the plastic analysis to determine the collapse mechanism of the tower under wind load.

\subsection{Description of the Tower}

The tower used in the analysis of this work was modelled using LinPro computer software. The modelling was carried out using the appropriate coordinates of joints and members. The height of the tower is $67.12 \mathrm{~m}$, the base width is $7.6 \mathrm{~m}$ and the top width is $2.0 \mathrm{~m}$. it was modelled with 31 joint and 54 
members. The profile of the tower was modelled with the elevation having sloped to a height of 42.72 $\mathrm{m}$ and straight to the remaining height. The slope was produced using the difference of $0.4 \mathrm{~m}$ and the height with a difference $6.1 \mathrm{~m}$. The sketch and screenshot of the modelled structure is shown in Figures 4 and 5 respectively. The tower is of square cross section and is provided with K-bracing at the lower part and X-Bracing at the higher part of the tower. The details of the selected tower are given in Tables 1 and 2.

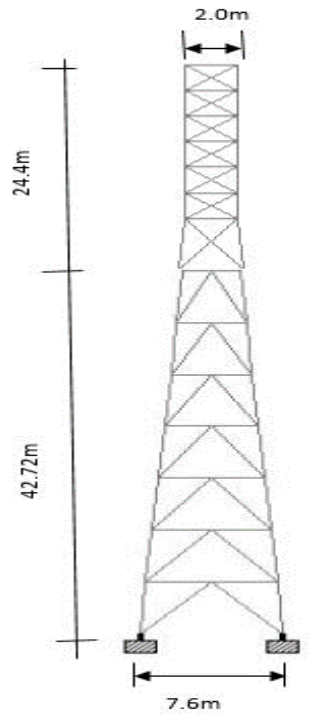

Figure 4: Tower Sketch

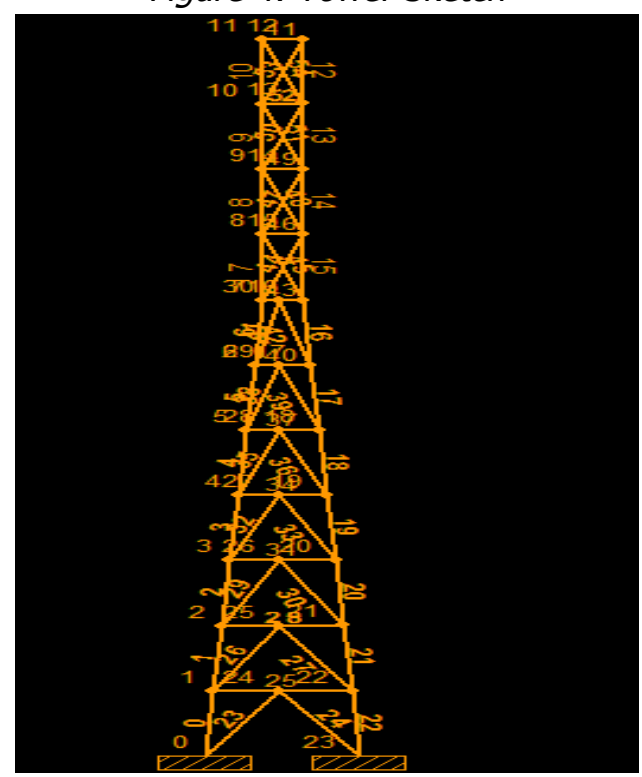

Figure 5: Screen shot of the Modelled Tower with LinPro2.7

Table 1: Geometric Details of the Towers

\begin{tabular}{ccc}
\hline $\begin{array}{c}\text { Tower height } \\
(\mathrm{m})\end{array}$ & $\begin{array}{c}\text { Base width } \\
(\mathrm{m})\end{array}$ & $\begin{array}{c}\text { Top width } \\
(\mathrm{m})\end{array}$ \\
\hline 67.12 & 7.6 & 2.0 \\
\hline
\end{tabular}

Nigerian Journal of Technology,
Table 2: Member Details of the Towers

\begin{tabular}{|c|c|}
\hline Member & Section \\
\hline Height & $67.12 \mathrm{~m}$ \\
\hline Legs (Column) (mm) & L150x150x15 \\
\hline $\begin{array}{l}\text { Diagonal bracing }(\mathrm{mm}) \\
\text { Horizontal bracing }(\mathrm{mm})\end{array}$ & $\begin{array}{l}\text { L80x80x8 } \\
170 \times 70 \times 7\end{array}$ \\
\hline
\end{tabular}

\subsection{Dead/Imposed loads}

The dead loads include the self-weight of the towers, which is taken as $564.8 \mathrm{kN}$, the antenna load is applied on the tower at a height of $46 \mathrm{~m}$ and it is taken as up to $10 \%$ of the dead load. Imposed loads on the platform is given as $2.5 \mathrm{kN} / \mathrm{m}^{2}$.

\subsubsection{Wind load}

The wind load on towers is normally determined by applying the total horizontal wind force on each tower section at the centre of each of the sections [12]. In this work the structures are divided into eleven (11) panels to enable the wind loading to be adequately modelled for the global analysis. The determination of the wind loads was carried out on the basis of [13]. The following nomenclatures were used in determining the wind loads on the tower; Wind load was determined using:

$$
\mathrm{F}=\mathrm{C}_{\mathrm{f}} \cdot \mathrm{q}_{\mathrm{z}} \cdot \mathrm{G} \cdot \mathrm{A}_{\mathrm{f}}
$$

Where, $F$, is the magnitude of the wind load, $C_{f}$, is a coefficient which takes into account the shape of the structure, in this case, the tower, $q_{z}$ is the wind pressure, $G$, is the gust coefficient, which takes into account the effects of the dynamic amplification (resonance) and lack of correlation of loads, and $A_{f}$, is the exposed area of the mast, projected onto the plane normal to the loads.

The following relations were used to determine the wind pressure, $\mathrm{q}_{\mathrm{z}}$ :

$$
\mathrm{q}_{\mathrm{z}}=0.613 \mathrm{~V}^{2}
$$

Where, $\mathrm{V}^{2}$, is the design wind speed

$$
\mathrm{V}^{2}=\mathrm{V} \cdot \mathrm{S}_{1} \cdot \mathrm{S}_{2} \cdot \mathrm{S}_{3}
$$

Where, $V$, is the basic wind speed $(42 \mathrm{~m} / \mathrm{s}, 45.8 \mathrm{~m} / \mathrm{s}$, $50 \mathrm{~m} / \mathrm{s}, 55 \mathrm{~m} / \mathrm{s}$ and $56 \mathrm{~m} / \mathrm{s}$ were used for zones 1,2 , 3,4 and 5 respectively), $S_{1}$, is topographic factor which equals 1(Except very exposed hill and valley shaped to produce a tunnelling of wind), $S_{2}$, is ground roughness factor for class $C$. Table 3 below shows the coefficients for calculating the wind load.

Table 3: Coefficients for Calculating Wind Loads

\begin{tabular}{ccccccc}
\hline Coefficient & $(\mathrm{G})$ & $\mathrm{A}_{\mathrm{f}}$ & $\mathrm{C}_{\mathrm{f}}$ & $\mathrm{S}_{3}$ & $\mathrm{~S}_{1}$ & $\mathrm{~S}_{2}$ \\
\hline Value & 0.85 & $0.57 \mathrm{~m}^{2}$ & 2.42 & 1.00 & 0.85 & 1 \\
\hline
\end{tabular}

Vol. 39, No. 4, October 2020 
Using the above coefficients, wind pressure on the tower was determined by:

$$
\begin{array}{lc}
\mathrm{q}_{\mathrm{z}}= & 0.613 \mathrm{~V}^{2} \cdot(0.85) \cdot(1) \cdot(1) \cdot(1) \\
\mathrm{q}_{\mathrm{z}}= & 0.52105 \mathrm{~V}^{2}
\end{array}
$$

But,

$$
\mathrm{V}^{2}=\mathrm{V} \cdot \mathrm{S}_{1} \cdot \mathrm{S}_{2} \cdot \mathrm{S}_{3}
$$

Using the basic wind speeds for all the zones, wind pressure and wind force is determined as presented in Section 4. (Table 4). The wind pressures determined for wind zones 1 and 5 were applied on the modelled tower for the determination of dynamic response of the structure to the wind load. The results are shown in Figures 6 and 7 respectively.

\subsection{Plastic Analysis}

As for the calculation of the wind loads across sections of the tower, the complete structure was divided into four section; section 1 , section 2 , section 3 , and section 4. The mid-point of each section is also determined and identified as $9.15 \mathrm{~m}, 27.45 \mathrm{~m}$, $42.70 \mathrm{~m}$ and 57.95 respectively. The total height of the tower is identified as $67.12 \mathrm{~m}$. Since the wind load on the tower proper is determined by applying the total horizontal wind force on each tower section at the centre of each of the sections [14], wind loads applied to sections acting at their mid points is determine using:

$$
F=\frac{\left(v^{2}\right)(A)}{390}
$$

Where, V2, is design wind speed, A, is area of tower face. The basic wind speed from all the zones were used for the calculation. These forces obtained at the mid-points were identified as F1, F2, F3, F4. The results are presented in section Four.

Analysing the tower as a rigid portal frame using the application of Kinematic theorem or Mechanism Method, the selected possible location for the plastic hinges is at the middle panels of the tower. Considering it as a portal frame, Figure 6 present a portal frame with constant plastic moment of resistance $\mathrm{Mp}$ throughout is subjected to two

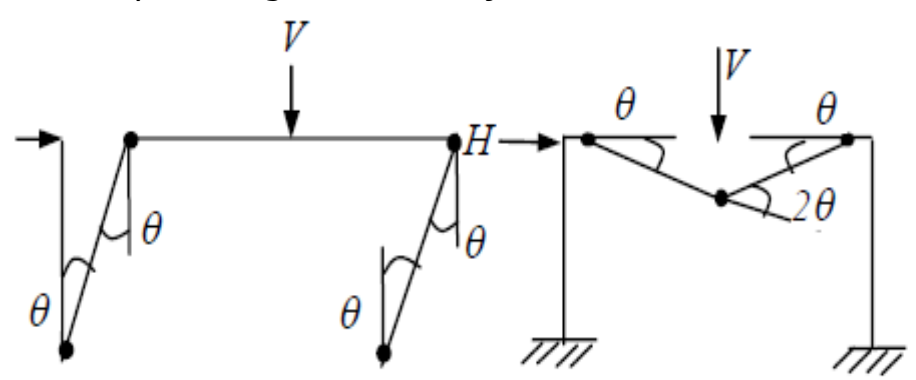

Figure 7: (a) Sway Mechanism (b) Beam Mechanism independent loads $\mathrm{H}$ and $\mathrm{V}$, while Figure 7 indicates the possible collapse mechanism. Considering the plastic moment, which is the largest bending moment that a section can withstand, the reduced plastic moment was obtained for the cross section. The plastic moment is thus;

$$
\mathrm{Mp}=\text { Z.fy }
$$

Where, $\mathrm{Mp}$ is the plastic moment, $\mathrm{Z}$ is sectional modulus and fy is the strength characteristic of the steel.

For beam mechanism, the following equations were used;

$$
\begin{aligned}
& \delta \mathrm{We}=\delta \mathrm{Wi} \\
& 6 \mathrm{~W} \theta=5 \mathrm{Mp} \theta \\
& \mathrm{W}=\frac{5}{6} \mathrm{Mp}
\end{aligned}
$$

For sway mechanism, the following equations were used in conjunction with (9);

$$
\begin{aligned}
& W \theta=3.5 \mathrm{Mp} \theta \\
& \mathrm{W}=\frac{7}{18} \mathrm{Mp}
\end{aligned}
$$

While as for combine mechanism, the following equations were used together with (9);

$$
\begin{aligned}
& 15 \mathrm{~W} \theta=4.5 \mathrm{Mp} \theta \\
& \mathrm{W}=\frac{3}{10} \mathrm{Mp}
\end{aligned}
$$

\section{RESULTS AND DISCUSSIONS}

\subsection{Calculations for the wind load}

Table 4 shows results for calculated effective wind pressure on the different panels of the tower using Equations 4 and 5 . The height of each panel is taken as $6.1 \mathrm{~m}$.

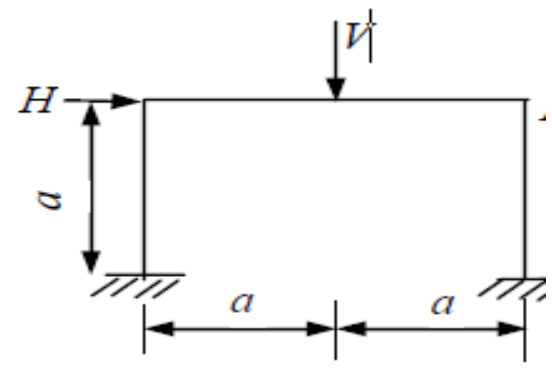

Figure 6: Loads on Tower

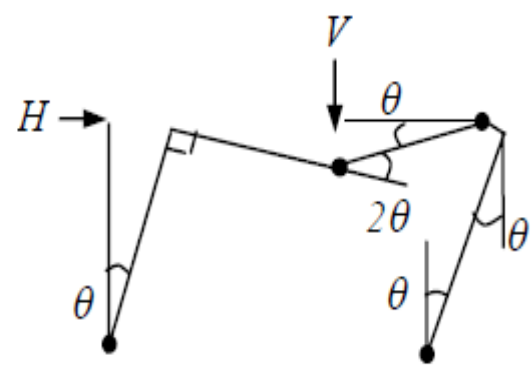

(c) Combine Mechanism 
Table 4: Effective Wind Pressure for 67.12m Tower using Nigerian Basic Wind Speed

\begin{tabular}{|c|c|c|c|c|c|c|c|c|c|}
\hline \multirow{2}{*}{$\begin{array}{c}\text { Panel } \\
\text { no. }\end{array}$} & \multirow{2}{*}{$\begin{array}{c}\text { Bottom } \\
\text { width }(\mathrm{m})\end{array}$} & \multirow{2}{*}{$\begin{array}{l}\text { Top width } \\
\text { (m) }\end{array}$} & \multirow{2}{*}{$\begin{array}{l}\text { Height of panel } \\
\text { from bottom }(m)\end{array}$} & \multirow[t]{2}{*}{$\mathrm{S}_{2}$} & \multicolumn{5}{|c|}{ Design wind pressure $\left(\mathrm{KN} / \mathrm{m}^{2}\right)$} \\
\hline & & & & & Z1 & $\mathrm{Z2}$ & Z3 & Z4 & $\mathrm{Z5}$ \\
\hline 1 & 10.3 & 9.72 & 6.12 & 0.98 & 1.23 & 1.34 & 1.41 & 1.55 & 1.63 \\
\hline 2 & 9.72 & 9.14 & 12.2 & 0.98 & 1.24 & 1.34 & 1.45 & 1.55 & 1.68 \\
\hline 3 & 9.14 & 8.56 & 18.3 & 1.05 & 1.26 & 1.36 & 1.46 & 1.65 & 1.71 \\
\hline 4 & 8.56 & 8.13 & 24.4 & 1.08 & 1.36 & 1.39 & 1.46 & 1.69 & 1.77 \\
\hline 5 & 8.13 & 7.87 & 30.5 & 1.10 & 1.39 & 1.44 & 1.55 & 1.73 & 1.80 \\
\hline 6 & 7.87 & 7.45 & 36.6 & 1.11 & 1.41 & 1.58 & 1.57 & 1.77 & 1.85 \\
\hline 7 & 7.45 & 7.14 & 42.7 & 1.13 & 1.45 & 1.59 & 1.60 & 1.78 & 1.88 \\
\hline 8 & 7.14 & 6.78 & 48.8 & 1.14 & 1.49 & 1.59 & 1.61 & 1.79 & 1.90 \\
\hline 9 & 6.78 & 5.62 & 54.0 & 1.14 & 1.49 & 1.62 & 1.62 & 1.80 & 1.94 \\
\hline 10 & 5.62 & 4.50 & 61.0 & 1.16 & 1.56 & 1.66 & 1.68 & 1.83 & 1.97 \\
\hline 11 & 4.5 & 2.0 & 67.12 & 1.17 & 1.56 & 1.69 & 1.72 & 1.84 & 1.99 \\
\hline
\end{tabular}

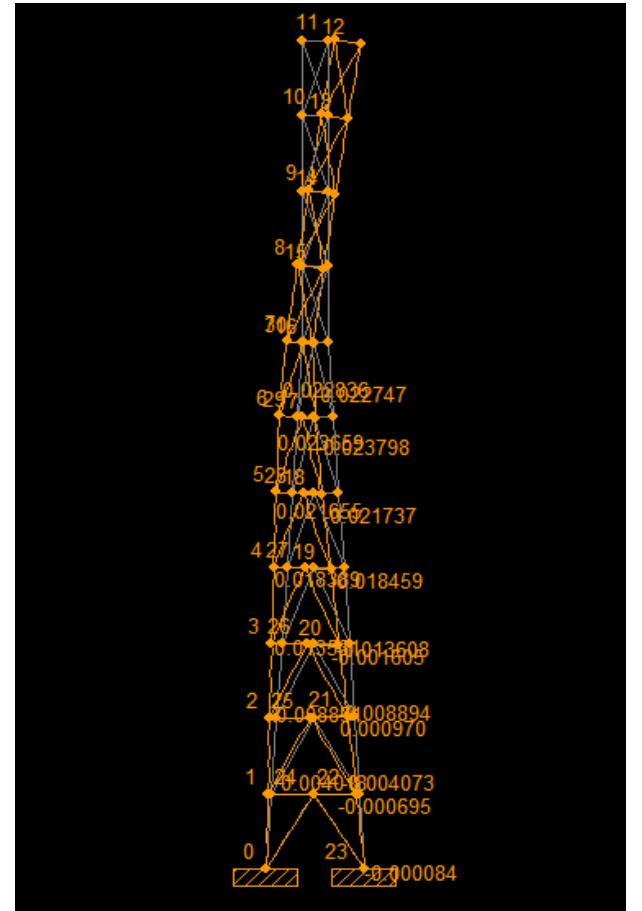

Figure 6: Joints Displacement using Wind pressure in Zone 1

It can be seen from Table 4 that wind pressure became more effective at the middle panel. Then it kept increasing along the height of the tower. It can be described as a quasi-static loading produced by fluctuations due to turbulence, though with frequencies too low to excite any resonant response at the zones where the pressure is low, but is high to excite resonant response to trigger collapse at the high pressure zones.

\subsection{Wind Load Simulation}

In order to determine the dynamic response of the structure to wind load, the wind pressures determined were used as load cases in LinPro 2.7

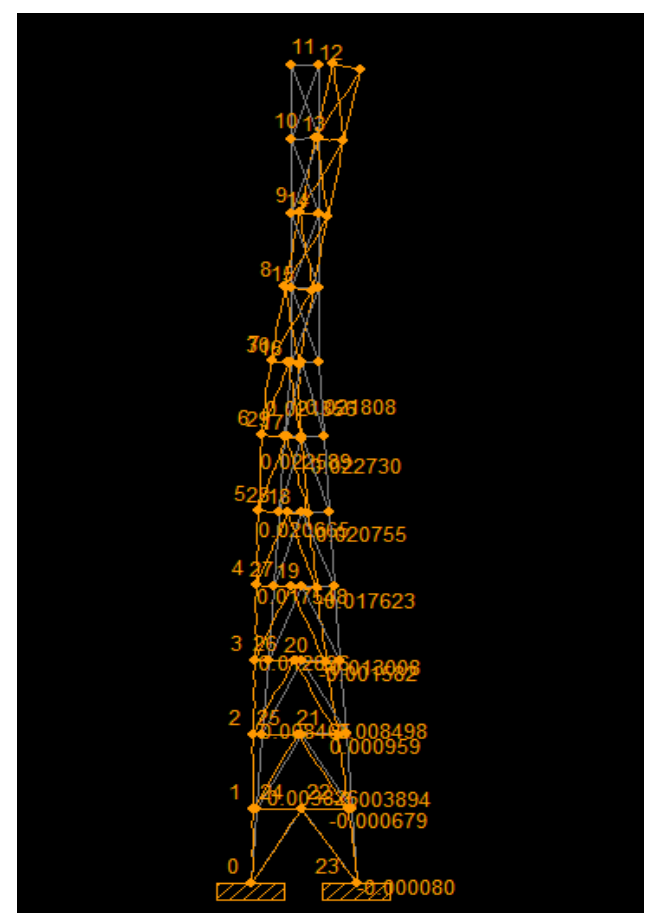

Figure 7: Joints Displacement using Wind pressure in Zone 5

computer software and was run for the analysis. Figures 8 and 9 shows the screen shots of results obtained.

In Figures 8 and 9 there is difference in joint displacement across all joints that is clear to indicate more vulnerability of the structures in these wind zone 1 to collapse as compared to other zones.

\subsection{Plastic Analysis}

For the purpose of plastic analysis of the tower, the tower was sectioned into four (4) different sections. Wind forces and moments at the midpoints of the sections were determined and plastic 
analysis was carried out on the tower sections. This was done using the collapse loads obtained from the plastic moment which is capable of triggering collapse of the structure.

The mechanism that has a lower value of collapse load is considered as dominant mechanism [15]. From Figure 10, it can be seen that the beam mechanism is higher followed by the sway mechanism and then combined mechanism. The rule is that the lowest mechanism is considered to be the most critical mechanism of collapse. In this case the combine mechanism is more critical at all sections of the tower. It is also obvious that when plastic hinges developed at the lower section ( $9.15 \mathrm{~m}$ from the base) of the tower, all the mechanisms are more critical compared to the other sections.

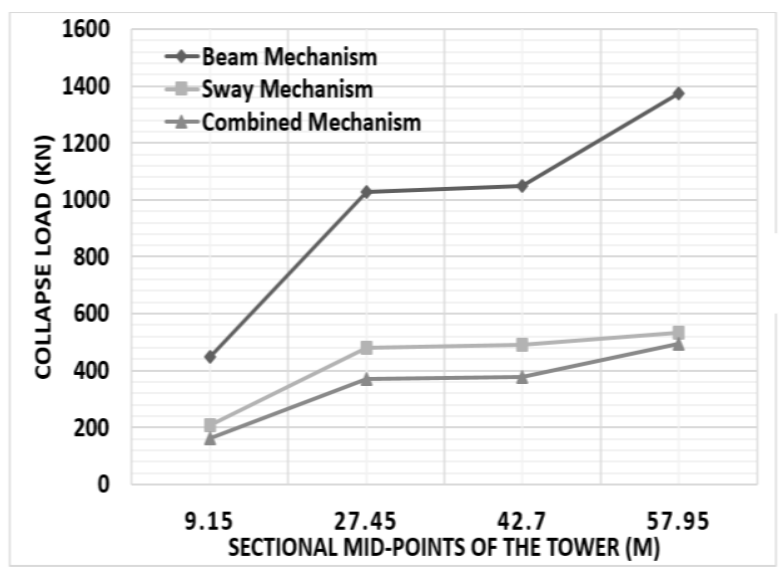

Figure 10: Collapse Loads for Different Mechanisms

\section{CONCLUSIONS}

On the basis of this study, the following conclusions are made;

i) Towers within the zone 5 basic wind speed are more vulnerable to collapse due to wind load owing to the fact that the wind resulted in higher joint displacement for this zone compared to the other wind zones.

ii) With the most severe Nigeria wind load, if the plastic hinges developed at the lower section of the tower, the three mechanisms are more critical compared to when it develops at other sections of the tower.

iii) With such load as the collapse load, if the plastic hinges developed at any section of the tower, combine mechanism is more critical and hence the tower will collapse due to failure of both leg members and bracing members.

\section{RECOMMENDATIONS}

Based on this work, it is recommended that

i) During the design of towers for telecommunication purposes in Nigeria, it should be bear in mind that the wind speeds are not uniform throughout the country.

ii) Each zone of the wind isopleths should be given its own peculiar consideration in terms of wind load.

iii) Also that the collapse radius for the towers should be provided as enshrined in the standards to mitigate damage to other structures and buildings in case the collapse load on the tower resulted sway mechanism.

\section{REFERENCES}

[1] Efthymiou E., G. S. "On the Structural Response of Steel Telecommunication Lattice Masts for Wind Loading and Combined Effects". EACWE $5,19^{\text {th }}-23^{\text {rd }}$ July, 2009, pp 1-11.

[2] Wahba, Y. M. Static and Dynamic Analyses of Guyed Mast, National Library of Canada, Canada, 1999.

[3] Dinu, F. "Mast,Ttowers and Chimneys", Mundus: European Erasmus. 2014, Retrieved from http://steel.fsv.cvut.cz/suscos Accessed on June 20, 2018.

[4] Mulherin, N. D. "Atmospheric Icing and Tower Collapse in the United States". 7th International Workshop on Atmospheric Icing of Structures (IWAIS'96) New Hampshire, USA, June 3-6 1996, pp. 1-11.

[5] Pham, K. "Earthquake Loadings and Steel Structures", CIRO Division of Building Construction and Engineering, Australia, 2001.

[6] Aliyu, M. and Abejide, O. S. "Finite Element Modelling of Steel Poles for Power Production and Transmissions", Nigerian Journal of Technology Vol. 38, No. 4, October 2019, pp. 840 - 847.

[7] Andersen, U. S. "Masts and Towers", Proceedings of the International Association for Shell and Spatial Structures (IASS) Symposium, Structural World Congress, SanFrancisco, 2009, pp. $127-138$. 
[8] Akoni, K. "Telecommunication Masts Collapse in Nigeria", LSWBC II, 12 - 14 May, 2014, pp 15-19.

[9] Onundi, L., Oumarou, M., \& Philip, O. "Classification of Nigerian Wind Isoplateths for Structural Purposes", Continental Journal. Engineering Sciences, Wilolud Online Journals, 2009 pp 48 - 55.

[10] Soboyejo, A.B.O. "Distribution of Extreme Winds in Nigeria", The Nigerian Engineer, 1971 7(3), $21-34$.

[11] "Guidelines on Technical Specifications for the Installation of Telecommunications Masts and Towers". National Communication Commission, Nigeria Issued on 9th Day of April, 2009.
[12] Travanty, F. (2001). "Tower and Antenna Wind Loading as a Function of Height", Retrieved from Noble Publishing Corporation, Norcross, Georgia, 2001.

[13] Eurocode 3: "Design of Steel Structures" Part 3-1: Towers, masts and chimneys Towers and masts. Brussels: CE; 2006.

[14] Sullins, E. J. "Analysis of Radio Communication Towers Subjected To Wind, Ice And Seismic Loadings", University of Missouri, Columbia, 2006.

[15] Asgarian, B., Eslamlou, S. D., Zaghi, A. E., \& Mehr, M. "Progressive collapse analysis of power transmission towers", Journal of Constructional Steel Research, Vol. 123, 2016, pp $31-40$. 